\title{
AVALIAÇÕES DA FLORESTA URBANA: LEVANTAMENTOS QUANTITATIVOS DA VEGETAÇÃO EM TÚNEIS VERDES DE PORTO ALEGRE, RS
}

\author{
URBAN FORESTRY EVALUATIONS: QUANTITATIVE SURVEYS ON VEGETATION \\ OF GREEN TUNNELS IN PORTO ALEGRE, RS
}

\section{Luciane Teresa Salvi}

Arquiteta e urbanista (UNIRITTER), bióloga (PUCRS), mestre em Gestão Urbana (PUCPR), professora do curso de Engenharia Ambiental e Sanitária da Faculdade Dom Bosco de Porto Alegre, e integrante do grupo de pesquisas Ornitologia Rio-grandense do Museu de Ciências e Tecnologia da Pontifícia Universidade Católica do Rio Grande do Sul - MCTPUCRS.

e-mail: salvilu@hotmail.com

\section{Cristiano Eidt Rovedder}

Biólogo (PUC-RS); integrante do grupo de pesquisas Ornitologia Rio-grandense do Museu de Ciências e Tecnologia da Pontifícia Universidade Católica do Rio Grande do Sul - MCTPUCRS.

e-mail: crovedder@yahoo.com.br

\section{Letícia Peret Antunes Hardt}

Arquiteta e urbanista (UFPR), doutora em Ciências Florestais (UFPR), professora titular do curso de Arquitetura e Urbanismo da Pontifícia Universidade Católica do Paraná - PUCPR.

e-mail: l.hardt@pucpr.br

\section{Carla Suertegaray Fontana}

Bióloga (PUCRS), doutora em Zoologia (PUCRS), curadora da coleção de aves do Museu de Ciências e Tecnologia da Pontifícia Universidade Católica do Rio Grande do Sul - MCTPUCRS e coordenadora do grupo de pesquisas Ornitologia Rio-grandense (MCTPUCRS).

e-mail:carla@pucrs.br

\section{RESUMO}

Os túneis verdes, objetos de estudo deste trabalho, constituem estruturas paisagísticas recorrentes na paisagem de Porto Alegre. Formados pela densa arborização viária, integram a floresta urbana da capital gaúcha e representam uma alternativa aos projetos dedicados ao fomento da vegetação em ambientes urbanizados. As propostas que objetivam a implantação desses túneis devem considerar o aumento da densidade e diversidade da flora, sendo necessária a realização de diagnósticos da vegetação existente como subsídio para a formulação de tais projetos. Esta pesquisa avalia aspectos referentes à diversidade e à composição das espécies vegetais formadoras de alguns túneis verdes da cidade de Porto Alegre, RS, estabelecendo um comparativo entre as espécies existentes, tendo em vista que o manejo dessa vegetação linear representa uma das ferramentas que pode ser empregada visando ao aumento da densidade e diversidade das florestas urbanas.

Palavras-chave: Gestão urbana, biodiversidade, arborização viária, levantamentos quantitativos, paisagem. 


\begin{abstract}
Green Tunnels, focus of this study, constitute structures of landscape that are currently found in Porto Alegre. Composed by dense tree lined streets, it integrates the urban forest of the capital of the State and represents an alternative to proposals concerning the vegetation improvement in the urban environment. The proposals that go through the implantation of those tunnels should consider the increasing of density and richness of flora, reason why studies that evolve surveys of the vegetation found on streets are an important subsidy to formulate those projects. This research evaluates aspects referring to diversity and composition of the tree species vegetation that form part of some green tunnels of Porto Alegre, RS, establishing a comparison between species and having in mind that the management of this kind of linear vegetation represents an alternative to increase density and diversity of urban forests.
\end{abstract}

Key words: Urban management, biodiversity, street arborization, quantitative surveys, landscape.

\title{
INTRODUÇÃO
}

Intitulada "cidade das árvores", Porto Alegre possui acima de um milhão e trezentas mil árvores distribuídas em suas ruas e avenidas, correspondendo a mais de 200 espécies entre nativas regionais e brasileiras, ou ainda originárias de outras procedências (PORTO ALEGRE, 2008; SANCHOTENE et al, 1998).

A valorização desse elemento vegetal pode ser constatada pela adoção da árvore como símbolo ecológico do município por meio da promulgação da Lei Municipal n. 8.245, de 10 de dezembro de 1998 (PORTO ALEGRE, 1998) e da elaboração do Plano Diretor de Arborização de Vias Públicas (PORTO ALEGRE, 2000), revisado na edição do Plano Diretor de Arborização Urbana de Porto Alegre (PORTO ALEGRE, 2007a). Ambos os documentos são de autoria da Secretaria Municipal do Meio Ambiente de Porto Alegre - SMAM e tratam, entre outros assuntos, de métodos para a preservação e manejo das árvores nas cidades e da importância da arborização como valores cultural e ambiental.

De acordo com Sanchotene et al (1998), desde o século 20 o plantio de árvores nas vias públicas tem integrado programas de planejamento urbano do município. Ao longo das décadas, entretanto, a compreensão do papel da vegetação transforma-se, originando diferentes concepções paisagísticas que orientam o trabalho dos técnicos da prefeitura. $O$ resultado, segundo os autores, é a formação pela arborização viária de "conjuntos paisagísticos peculiares [...] que caracterizam estéticas e compreensões de época e determinam a identidade de ruas, avenidas e até bairros inteiros da cidade" (SANCHOTENE et al, 1998, p. 133).

Um exemplo desse tipo de conjunto paisagístico e objeto de estudo deste trabalho é o túnel verde formado pela densa arborização viária que, ao ser disposta em ambos os lados das vias e com reduzida distância entre espécimes, é responsável pela geração de contínuo sombreamento. Esse efeito é resultante do encontro das copas das árvores que se unificam, formando, visualmente, um maciço linear suspenso sobre a via urbana (Figura 1).

Implantada pela prefeitura entre as décadas de 1930 e 1940 - Sanchotene et al, 1998 - essa arborização de grande porte sofria podas anuais de modo a evitar seu 


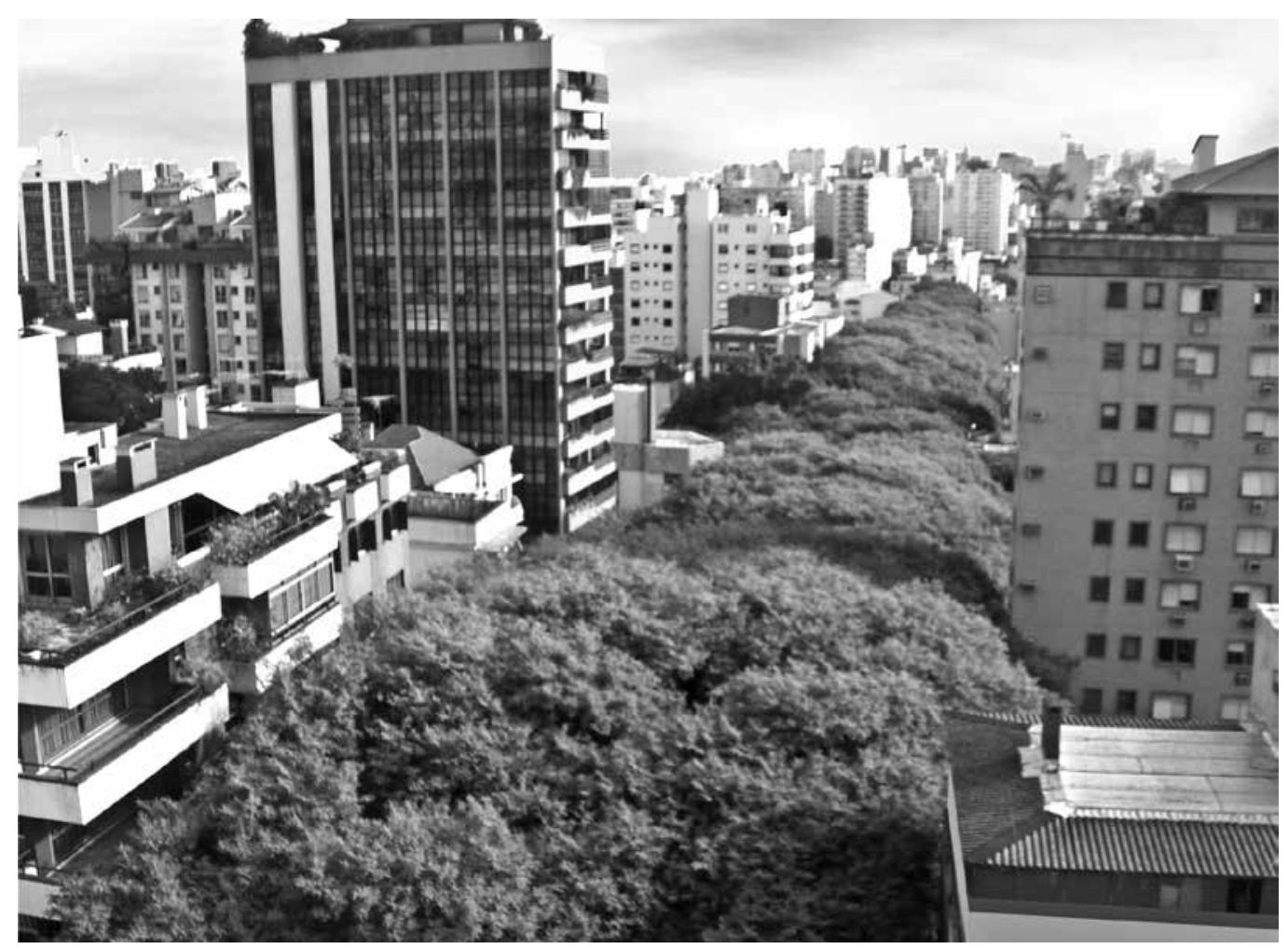

Figura 1: Túnel verde existente na rua Gonçalo de Carvalho, bairro Independência, Porto Alegre, RS. Composição paisagística formada por exemplares de tipuanas (Tipuana tipu)

Fonte: Luciane Salvi

contato com a rede elétrica aérea. Nas décadas seguintes, entretanto, a poda deixou de ser praticada e os exemplares passaram a desenvolver-se verticalmente, constituindo os túneis verdes existentes na atualidade. Os autores salientam que as espécies utilizadas nesses plantios eram, freqüentemente, importadas, como é o caso da Tipuana tipu procedente da Argentina.

Esse tipo de composição arbórea contribui para o aumento da qualidade de vida nas cidades, aprimorando a ambiência urbana de diversos modos. Segundo Biondi e Althaus (2005) e Mascaró e Mascaró (2002), a vegetação, especialmente aquela de porte arbóreo, age sobre os microclimas urbanos, ameniza a radiação solar na estação quente e modifica a temperatura, a umidade relativa do ar e a direção dos ventos, a lém de atuar como barreira acústica, reduzir a polvição atmosférica e, quando em grandes quantidades, interferir na freqüência das chuvas. Devem ser somados a esses benefícios os efeitos psicológicos gerados pela presença dos elementos naturais no ambiente, como o bem-estar proporcionado pelo sombreamento das árvores nas estações quentes. Na malha urbana são criados locais de repouso, de interações sociais, de lazer e de contemplação - parte da beleza dessas áreas é proporcionada por paisagens naturais ou antrópicas (em espaços que utilizam, como fatores compositivos de projeto, aspectos intrínsecos da vegetação como porte, coloração, forma, floração, perfume, textura, entre outros). 
Os túneis verdes desempenham, ainda, papel de corredores de vegetação para avifauna (SALVI, 2008), servindo como elemento atrativo às aves, oferecendo regiões alternativas de descanso, nidificação, alimentação e abrigo para uma variedade de espécies, auxiliando na perpetuação da avifauna em ambientes densamente urbanizados.

Em decorrência de mobilização popular, três túneis se encontram tombados na cidade, tendo sido elevados a patrimônio cultural, histórico e ecológico de Porto Alegre; localizam-se na rua Gonçalo de Carvalho, no bairro Independência; na rua João Mendes Ouriques, no bairro lpanema e na rua Marquês do Pombal, no bairro Moinhos de Vento (PORTO ALEGRE, 2006a, 2007b, 2007c, 2008). A Figura 2 ilustra parte da repercussão desses atos na mídia local.

\section{Túnel verde é patrimônio da cidade}

Prefeitura decreta a preservação das tipuanas e do calçamento de um trecho da Marquês do Pombal

\begin{tabular}{|c|c|}
\hline risticas locais & $\begin{array}{l}\text { lom- } \\
\text { de de } \\
\text { çado } \\
\text { bien- } \\
\text { gora } \\
\text { á de } \\
\text { ue a } \\
\text { irá a } \\
\text { acon- } \\
\text { lho e } \\
\text { te da } \\
\text { Moi- }\end{array}$ \\
\hline
\end{tabular}

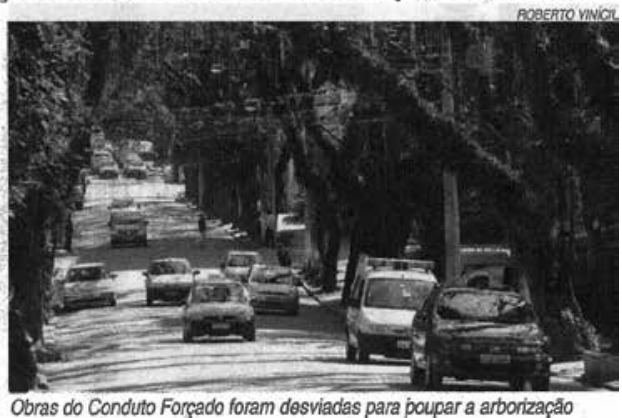

Figura 2: Reportagem veiculada em periódico que noticia a elevação de túnel verde da rua Marquês do Pombal a status de patrimônio cultural, histórico e ecológico de Porto Alegre

Fonte: TÚNEL, 2007, p. 14

Considerando que os túneis verdes são formados a partir de plantios antigos realizados nos logradouros e danos podem ser provocados pela eventual queda de árvores, a prefeitura de Porto Alegre, a partir da Lei Municipal n. 551, de 8 de junho de 2006 (PORTO ALEGRE, 2006b), estabelece a compensação do crédito tributário do Imposto sobre Propriedade Territorial Urbana - IPTU, resultante de indenização por danos em bem imóvel localizado nesses logradouros. A regulamentação dessa lei representa mais um elemento que demonstra a identificação da relevância dos túneis verdes para a cidade, uma vez que é criado um instrumento legal para ser aplicado em eventuais acidentes, refletindo o interesse da administração pública na perpetuação dessas estruturas paisagísticas na malha urbana.

A preocupação histórica da administração pública municipal com a arborização viária, a identificação da singularidade dos túneis verdes na paisagem urbana e sua valorização pelos cidadãos e poder público demonstram o reconhecimento da importância dos túneis verdes como um dos vários elementos que compõem a identidade da capital gaúcha. Em detrimento do papel exercido por essas estruturas paisagísticas, o 
presente trabalho realiza levantamentos quantitativos da vegetação, buscando avaliar aspectos referentes à diversidade e à composição (densidade e relação entre número de espécies exóticas e nativas) das espécies vegetais formadoras de alguns túneis verdes da cidade de Porto Alegre. O estudo também estabelece um comparativo das espécies encontradas nessas ruas com aquelas presentes em vias controle, analisando o grau de similaridade existente. Cabe salientar que as vias controle apresentam, essencialmente, vegetação de porte médio e baixo, situada de modo esparso no calçamento e, por vezes, implantada pelos próprios moradores locais e não pela prefeitura. Os controles são próximos aos túneis estudados, apresentam mesma direção e características semeIhantes como uso e ocupação do solo e largura de via, diferenciando-se, basicamente, por serem destituídos de vegetação que produz o efeito de túnel.

Os principais objetivos desta pesquisa consistem na reunião de informações e na elaboração de considerações úteis ao planejamento da arborização viária, tendo em vista que o manejo dessa vegetação linear representa uma das ferramentas a qual pode ser empregada visando ao aumento da densidade e diversidade das florestas urbanas.

\section{REFERENCIAL TEÓRICO}

\section{Florestas urbanas}

A expressão "floresta urbana" é utilizada por alguns autores para descrever o somatório de toda a vegetação existente em ambientes urbanos, dentre os quais se incluem o centro da cidade, as áreas residenciais, os subúrbios e a periferia (MOCK, 2006). Para Girling e Kellett (2005), o conceito reúne, além da vegetação, o solo e seus microrganismos, insetos, seres humanos e demais formas de vida existentes nesse espaço que combina elementos naturais e construídos. A floresta urbana possui três componentes essenciais que devem ser considerados pelos profissionais envolvidos nos projetos de arborização: vegetação saudável, manejo abrangente e apoio comunitário (MOCK, 2006). O fator vegetação saudável inclui, entre outros elementos, a qualidade dos exemplares utilizados nos projetos de arborização, a heterogeneidade de idades e a combinação de espécies, de modo a obter-se proteção contra eventos climáticos ou ataques de pragas e enfermidades. $\bigcirc$ incremento da diversidade das espécies utilizadas é particularmente relevante para a manutenção e sobrevida da flora, uma vez que espécies vegetais distintas apresentam diferentes taxas de crescimento, longevidade e capacidade de resistir a pragas e doenças. A floresta urbana deve buscar a diversidade, evitando a geração de grandes extensões de vegetação homogênea. Recomenda-se que sua composição seja formada por, no máximo:

$10 \%$ de cada espécie;

20\% do mesmo gênero;

30\% da mesma família (MOCK, 2006). 
A utilização de um porcentual mínimo de 70\% de espécies nativas regionais também é recomendável, conforme diretrizes estabelecidas pela Secretaria Municipal do Meio Ambiente de Porto Alegre - SMAM para a promoção da biodiversidade e preservação da floresta urbana (PORTO ALEGRE, 2007a).

Por manejo abrangente entende-se um conjunto de atividades diversificadas, como o manejo individual de cada árvore e também de seus grupos, a educação ambiental da comunidade e a coordenação das instituições responsáveis pela manutenção das florestas urbanas, de forma a promover a integração de suas ações e a inclusão das questões ambientais nos processos de planejamento. Essas ações, entretanto, não possuem sobrevida se o terceiro item, o apoio da comunidade, não for obtido, uma vez que é a opção dos cidadãos pela manutenção das florestas e ecossistemas urbanos o elemento essencial para o estabelecimento de novas práticas, políticas e formas de gerenciamento (MOCK, 2006).

Torna-se fundamental, portanto, que os cidadãos e os órgãos governamentais considerem todo o patrimônio natural de uma cidade como parte da infra-estrutura urbana, sendo tratado de modo planejado e integrado, da mesma forma como acontece com os sistemas de saneamento, transporte, energia, etc. (GIRLING; KELLETT, 2005; WOLF, 2004). Senna (2002) concorda com essa visão de gerenciamento quando afirma ser necessária a existência de infra-estrutura específica no município para a gestão das áreas verdes urbanas e as cidades, independentemente de seu porte, devem possuir um serviço municipal de administração capaz de realizar ações de planejamento, implementação e gestão dessas áreas. A autora destaca, ainda, que a ação do município é também essencial para manter a integridade das áreas de preservação permanente inseridas em áreas urbanas. Tal responsabilidade lhe é atribuída a partir das alterações introduzidas no art. n. 22 da Lei Federal n. 4.771, de 15 de setembro de 1965 - Código Florestal Brasileiro (BRASIL, 1965) - por meio da promulgação da Lei Federal n. 7.803, de 18 de julho de 1989 (BRASIL, 1989).

\section{Arborização viária}

Segundo Milano (1988' apud MILANO, 1990), o processo de planejamento da arborização viária pelos municípios deve considerar:

a) $\bigcirc$ ambiente urbano - caracterizado seu clima, solos e qualidade do ar;

b) o espaço físico disponível - definido pela largura de ruas e calçadas, afastamento predial, ocorrência e posicionamento de redes aéreas e subterrâneas;

c) as características das espécies a utilizar - avaliada a adaptabilidade climática, resistência a pragas e doenças, tolerância à polvição e características morfológicas e fenológicas (forma, porte, raiz, floração e frutificação, entre outras).

É recomendável que esses elementos integrem os planos de arborização municipais, que devem ser dinâmicos e capazes de responder a quatro questões essenciais: o quê 
plantar, onde, quando e como (MILANO, $1987^{2}$ apud MILANO, 1990). A composição de um plano de arborização de ruas necessita seguir as seguintes etapas (BIONDI, 2000):

a) Estabelecimento de objetivos - podendo ser gerais ou específicos e envolvendo diversas situações, desde a melhoria da qualidade de vida nos ambientes urbanos, até o sombreamento de ruas;

b) elaboração de anteprojeto - corresponde ao diagnóstico com detalhada análise das características do local e da vegetação existente, envolvendo também dados históricos da cidade;

c) desenvolvimento de plano - compreende a implantação (quando, quanto, como e onde plantar); o manejo (ações para a manutenção do vigor das árvores); e o monitoramento (acompanhamento dos plantios);

d) organização de banco de dados - comporta o armazenamento de informações geradas pelos dados colhidos durante o monitoramento;

e) replanejamento - engloba a análise e avaliação do plano de arborização implantado, o qual é alimentado pelas informações contidas no banco de dados.

Para ilustrar a dinâmica desse processo de planejamento, Milano (1987 apud MILANO, 1990) apresenta o fluxograma da Figura 3.

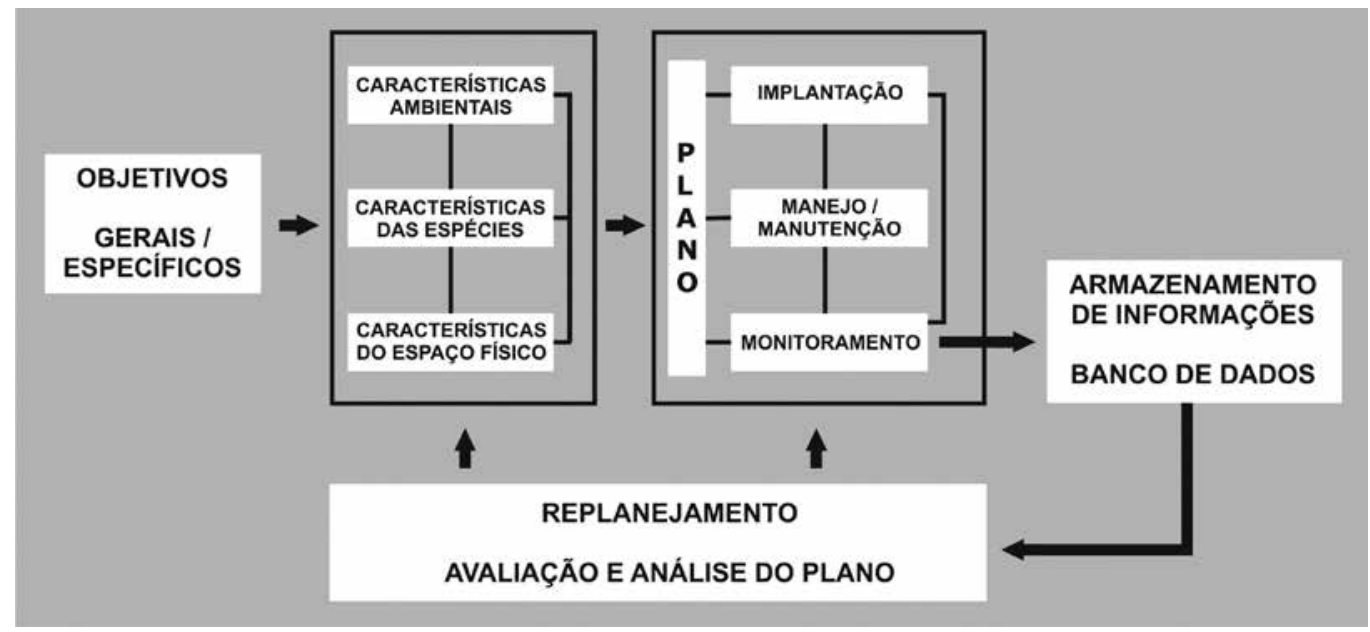

Figura 3: Fluxograma de planejamento da arborização viária Fonte: MILANO (1987 apud MILANO, 1990, p. 60-71)

De acordo com Biondi (2000), um planejamento adequado da arborização viária exige um processo inicial que consiste em sua avaliação, etapa que torna viável o aperfeiçoamento das práticas de manejo, o diagnóstico para o replanejamento e o apoio para o planejamento de novas áreas. Existem, entretanto, procedimentos distintos que podem ser adotados nessas avaliações.

Segundo Milano e Dalcin (2000), os inventários da arborização de ruas podem possuir caráter quantitativo, qualitativo ou quali-quantitativo, e os objetivos da avaliação 
são determinantes para a definição do melhor sistema a ser adotado. As avaliações podem ainda ser totais - indicadas quando o objetivo é a realização de cadastro, ou para avaliações qualitativas em cidades pequenas - ou por amostragem, método que se mostra adequado para levantamentos quantitativos e também qualitativos (MILANO; DALCIN, 2000). Esses autores citam, como exemplos de aspectos qualitativos, a determinação das tipologias florestais básicas existentes - áreas de florestas remanescentes, de reflorestamento, etc., assim como a classificação das condições da vegetação em categorias como boa, satisfatória e ruim - conforme o estado de conservação dos exemplares analisados.

As informações obtidas a partir desses processos de avaliação são fundamentais para as ações de replanejamento dos planos de arborização, permitindo a seleção das espécies mais adequadas a cada situação urbana em particular.

\section{PROCEDIMENTOS METODOLÓGICOS}

\section{Estudo de caso:}

\section{a cidade de Porto Alegre e a seleção dos túneis verdes}

Porto Alegre, capital do estado do Rio Grande do Sul, localiza-se sob a latitude de $30^{\circ} 01^{\prime} 59^{\prime \prime} \mathrm{S}$ e a longitude de $51^{\circ} 13^{\prime} 48^{\prime \prime} \mathrm{W}$ e na altitude de $4 \mathrm{~m}$ s.n.m. em seu marco rodoviário zero, na praça Montevidéu, no centro da cidade (MENEGAT et al, 1998). Os 83 bairros do município distribuem-se em dez macrozonas, as quais abrigam uma população estimada em 1.440 .939 habitantes (IBGE, 2006).

Os cinco túneis verdes selecionados para o estudo estão situados em diferentes bairros da capital gaúcha e abrigam densa vegetação composta, essencialmente, por exemplares de porte arbóreo, dispostos em ambos os passeios (Figura 4).

A seleção dos túneis verdes leva em consideração os seguintes aspectos: a) sua inserção em macrozona plenamente urbanizada; b) sua composição por, pelo menos, duas quadras consecutivas de densa vegetação de porte arbóreo (critério arbitrado em função da menor extensão de vegetação contínua apresentada por três túneis verdes selecionados pela pesquisa); c) existência de rua próxima ao túnel e de mesma direção utilizada como controle. A rua de controle apresenta características urbanas semelhantes às do túnel, como uso e ocupação do solo, largura de via, etc., diferenciando-se, basicamente, por ser destituída de vegetação que produz o efeito de túnel.

\section{Coleta de dados da vegetação}

Todos os túneis verdes e vias controle selecionados foram percorridos a pé e cada árvore recebeu um número, sendo identificada segundo espécie. Os vegetais desconhecidos foram fotografados e tiveram um ramo colhido e acondicionado em saco plástico com sua respectiva identificação (abreviatura da rua seguida da numeração atribuída ao exemplar). Esse material foi utilizado para sua posterior classificação, contando-se com o auxílio de chave sistemática proposta por Souza e Lorenzi (2005) 


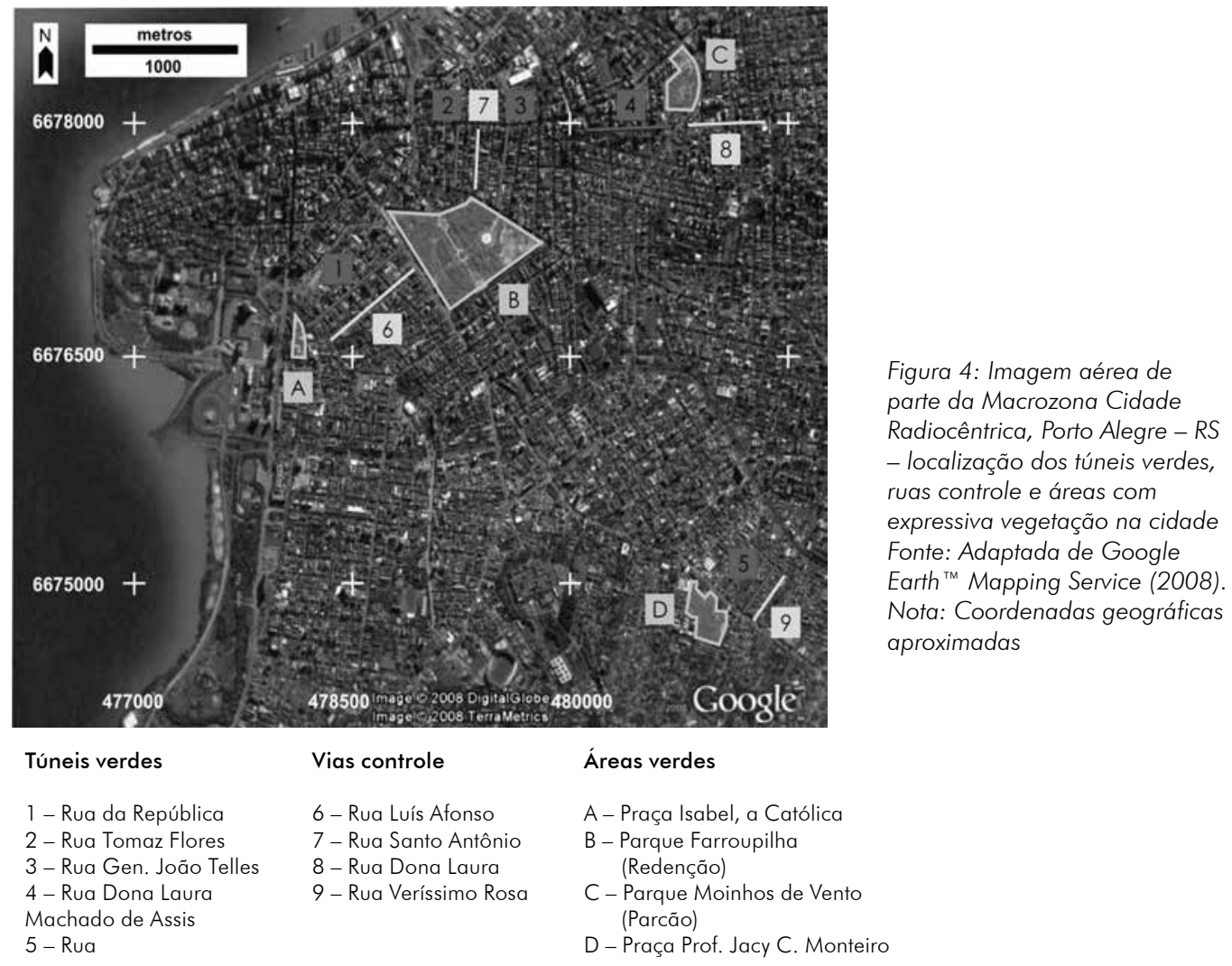

e bibliografia especializada, como Lorenzi (2002a, 2002b) e Lorenzi et al (2003), entre outros. Plantas de menor porte, arbustivas ou trepadeiras, que se encontravam sobre as árvores também foram identificadas, recorrendo-se a Lorenzi e Souza (2001). Se, após esse trabalho de classificação, a espécie vegetal permanecesse indeterminada, era solicitado o auxílio de especialistas do Museu Botânico Municipal de Curitiba ou do Departamento de Botânica da Fundação Zoobotânica do Rio Grande do Sul.

\section{Tratamento dos dados}

O tratamento quantitativo dos dados relativos à vegetação amostrada consistiu no cálculo dos porcentuais de cada espécie vegetal registrada em cada túnel verde e via controle, com a definição das totalidades das espécies, famílias e classificação entre exóticas e nativas, de modo a gerar informações acerca da diversidade de vegetação que compõe a arborização das ruas estudadas ${ }^{4}$. A partir dos resultados gerados, foi feita a análise de agrupamento com base na similaridade da abundância ${ }^{5}$ da vegetação, utilizando-se o software Biodiversity Pro 3.2 (McALEECE, 1997). Importante salientar que valores porcentuais são usualmente empregados em estudos que tratam de vegetação, e o item abundância se refere à porcentagem dos indivíduos presentes em uma determinada amostra (ODUM; BARRETT, 2008).

O índice de associação escolhido para o cálculo da similaridade foi o Bray-Curtis, por representar uma das medidas de distância mais robustas para ordenar correlações 
lineares, sendo amplamente utilizado pelas ciências ambientais (FAITH; MINCHIN; BELBIN, 1987).

\section{RESULTADOS E DISCUSSÃO}

A coleta de dados da vegetação ocorreu nos meses de março, abril, maio, setembro, outubro e dezembro de 2007. A coleta desses dados não obedeceu a uma periodicidade, uma vez que esse fator não era significativo para o levantamento das espécies vegetais existentes nas vias. Como resultado dos levantamentos da composição vegetal de cinco túneis verdes e quatro trechos controle, tem-se o registro de 758 exemplares vegetais (Tabela 1).

Tabela 1 - Número de exemplares vegetais alvo de levantamentos e sua densidade por via

\begin{tabular}{|c|c|c|c|}
\hline $\begin{array}{c}\text { VIA ALVO DE } \\
\text { LEVANTAMENTO }\end{array}$ & $\begin{array}{c}\mathrm{A}- \\
\mathrm{N}^{\circ} \text { EXEMPLARES } \\
\text { VEGETAIS }\end{array}$ & 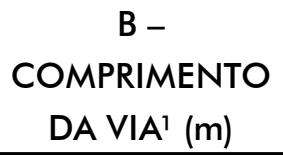 & $\begin{array}{c}\text { DENSIDADE DA } \\
\text { VEGETAÇÃO }{ }^{2} \\
\text { (A / B) }\end{array}$ \\
\hline Rua Gen. João Telles & 99 & 573,28 & 0,17 \\
\hline Rua Tomaz Flores & 89 & 416,31 & 0,21 \\
\hline $\begin{array}{l}\text { Rua Santo Antônio } \\
\text { (controle) }\end{array}$ & 23 & 485,29 & 0,05 \\
\hline Rua da República & 177 & 911,64 & 0,19 \\
\hline Rua Luiz Afonso (controle) & 57 & 701,28 & 0,08 \\
\hline Rua Dona Laura & 79 & 574,01 & 0,14 \\
\hline Rua Dona Laura (controle) & 42 & 396,90 & 0,10 \\
\hline Rua Machado de Assis & 81 & 350,54 & 0,23 \\
\hline $\begin{array}{l}\text { Rua Veríssimo Rosa } \\
\text { (controle) }\end{array}$ & 113 & 351,79 & 0,32 \\
\hline TOTAL & 760 & & \\
\hline
\end{tabular}

Notas: (1) Dados obtidos a partir de imagens georreferenciadas pelo estudo

(2) Densidade de vegetação conforme Fernández-Juricic (2000)

Os dados obtidos ao término dos levantamentos realizados nas nove vias de estudo são demonstrados no Quadro 1.

A baixa diversidade de espécies vegetais constatada (identificadas apenas 61 espécies distintas, 25 nativas e 36 exóticas, pertencentes a 33 famílias botânicas) é verificada, principalmente, entre os túneis verdes, e os existentes nas ruas Dona Laura e Machado de Assis são os que evidenciam a menor variedade de espécies entre todas as ruas analisadas (apenas sete espécies vegetais em cada trecho pesquisado - Quadro 1). Essa situação é resultante das práticas de plantio usuais das décadas de 1930 e 1940 na cidade, as quais selecionavam reduzido número de espécies para inserção nos logradouros. 


\section{Quadro 1: Síntese dos resultados obtidos nos levantamentos}

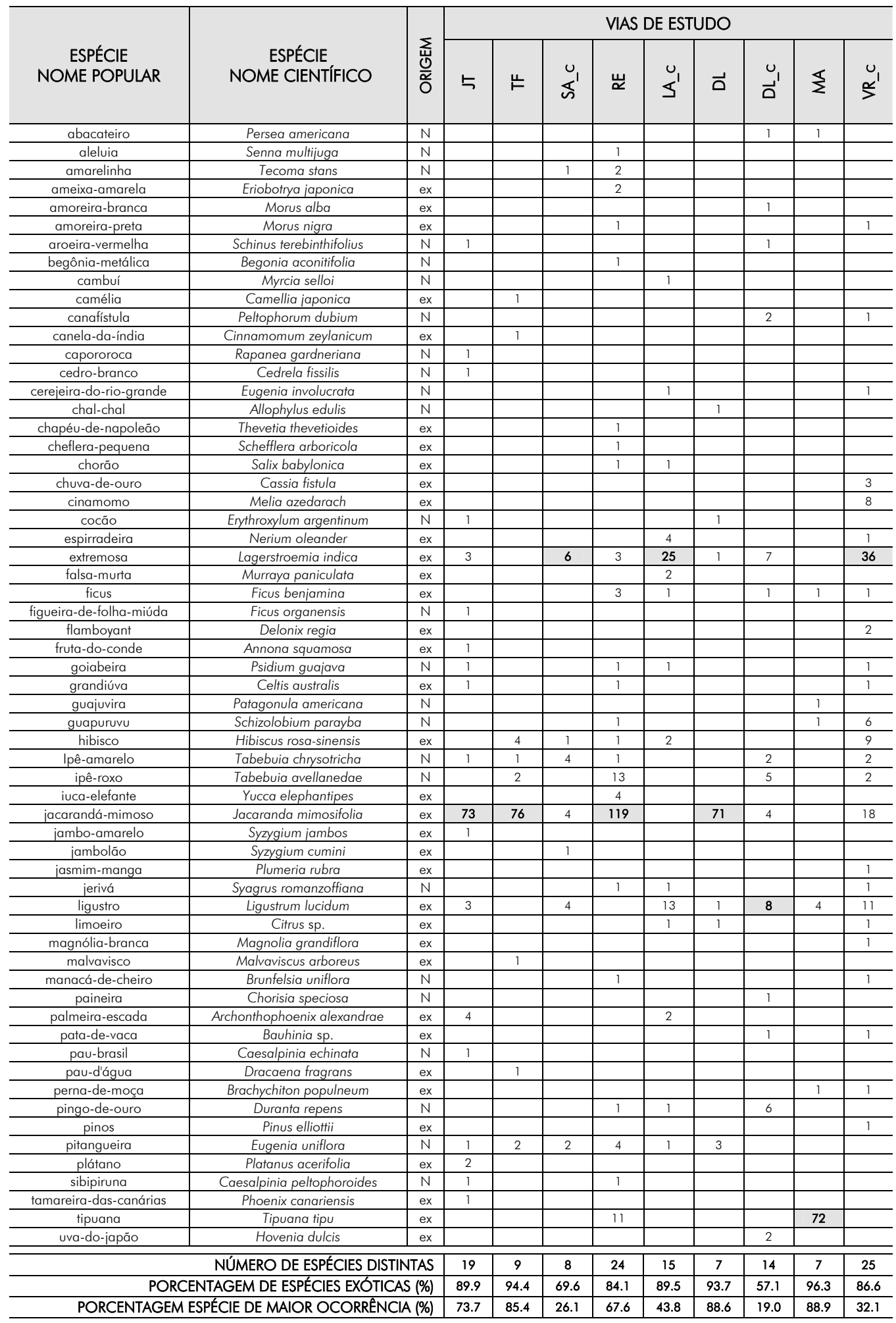

Notas: JT - General João Telles; TF - Tomaz Flores; SA_C - Santo Antônio (controle); RE - República; LA_C - Luiz Afonso (controle); DL - Dona Laura; DL C - Dona Laura (controle); MA - Machado de Assis; VR C - Veríssimo Rosa (controle); $N$ - espécie nativa; ex-espécie exótica. Célula destacada em cinza: espécie vegetal de maior representatividade na via. 
As espécies vegetais predominantes nos cinco túneis pesquisados registram porcentagens que oscilam de 67,6\% (jacarandá-mimoso - Jacaranda mimosifolia - na rua da República) até 88,9\% de ocorrência (tipuana - Tipuana tipu - na Rua Machado de Assis), valores superiores aos máximos recomendados por Mock (2006) para a constituição de florestas urbanas (10\% de uma mesma espécie e 30\% de uma mesma família botânica). Entre as vias controle, a densidade da vegetação diminui, porém a heterogeneidade de espécies e famílias botânicas aumenta, possivelmente em decorrência da participação autônoma dos moradores locais no plantio de árvores nos logradouros, o que acaba refletindo sobre a composição da vegetação.

Esses dados demonstram acentuada homogeneidade da vegetação nos túneis verdes, situação que deve ser compensada em novos projetos de arborização viária em ruas adjacentes às estudadas, por meio da implementação de um maior número de espécies botânicas, promovendo um aumento na diversidade da flora local. É importante salientar que não se recomenda a eliminação da tipologia de túnel verde na malha urbana, mas se sugere a inclusão de novas diretrizes aos projetos de arborização, contemplando questões pertinentes e atuais, como o fomento à biodiversidade em ambientes construídos na busca de cidades sustentáveis.

Quanto à origem da vegetação, observa-se uma proporção elevada de espécies exóticas nas vias, contrariando a orientação atual definida no Plano Diretor de Arborização de Porto Alegre (PORTO ALEGRE, 2007a), a qual recomenda a implantação de um porcentual mínimo de 70\% de espécies nativas. A porcentagem de espécies exóticas encontrada (Quadro 1) oscila de 57,1\% (rua Dona Laura controle) até 96,3\% (rua Machado de Assis), e o cálculo da média entre as nove vias pesquisadas alcança $84,6 \%$. Esses valores elevados chamam a atenção para a necessidade de buscar-se a implantação de vegetação nativa na paisagem urbana, conforme defendido por Reis et al (2003) e Sanchotene (1990), buscando-se a estabilidade e a preservação da floresta urbana e da biodiversidade (PORTO ALEGRE, 2007a).

Cabe salientar que o aumento do emprego de vegetação nativa não representa, de forma alguma, a extinção dos túneis verdes. $\bigcirc$ processo de implantação desses corredores urbanos de vegetação deve apenas considerar o incremento da diversidade de espécies implantadas nos logradouros, por meio da utilização de vegetais nativos e de diversos portes. $\bigcirc$ plantio de ampla gama de espécies contribui para a formação de uma floresta urbana mais heterogênea e complexa, fatores relevantes para a manutenção da biodiversidade, especialmente para a avifauna, conforme citado por Fernández-Juricic (2000).

A análise comparativa dos resultados, considerando a similaridade da abundância da vegetação encontrada nos corredores verdes e controles, mostra que os corredores verdes mais semelhantes são os existentes nas ruas Tomaz Flores e Dona Laura, com $89,7 \%$ de similaridade e que, entre os controles, o maior grau de similaridade é constatado entre as vias Santo Antônio e Dona Laura, com porcentagem de 61,9\% (Figura 5 e Quadro 2). Observa-se a formação de um grupo de vias com alto grau de semelhança $(85,5 \%)$, composto pelas ruas General João Telles, Tomaz Flores e Dona 
Laura, grupo similar em 62,1\% à rua da República. A rua Machado de Assis, em função de ser a única via densamente arborizada com exemplares de tipuanas (Tipuana tipu), é a que mais se difere, chegando a apresentar $0 \%$ de similaridade com o túnel da rua Tomaz Flores (Figura 5 e Quadro 2).

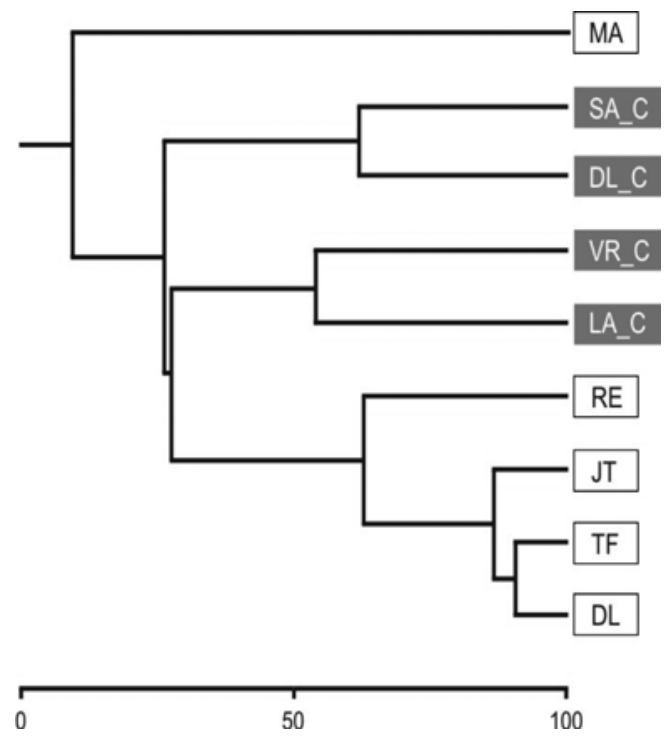

Figura 5: Análise de agrupamento com base na similaridade da abundância da vegetação relações expressas em porcentagens

Notas:

MA - Machado de Assis;

SA_C - Santo Antônio (controle);

DL C - Dona Laura (controle);

VR_C - Veríssimo Rosa (controle);

LA_C - Luiz Afonso (controle);

RE-República;

JT - General João Telles;

TF - Tomaz Flores;

DL - Dona Laura.

\begin{tabular}{|c|c|c|c|c|c|c|c|c|c|}
\hline & $\mathrm{DL}$ & DL_C & JT & LA_C & MA & RE & SA_C & $\mathrm{TF}$ & VR_C \\
\hline $\mathrm{DL}$ & * & 12 & 85,8824 & 3,2787 & 1,2903 & 59,6639 & 13,0435 & 89,7436 & 23,5294 \\
\hline DL_C & * & * & 18,3333 & 25 & 9,5238 & 10,6383 & 61,9048 & 13,2076 & 26,6667 \\
\hline JT & * & * & * & 11,2676 & 3,4286 & 58,9147 & 17,8571 & 79,5455 & 27,3684 \\
\hline LA_C & * & * & * & * & 6,2992 & 4,7619 & 25 & 1,5625 & 53,5211 \\
\hline MA & * & * & * & * & * & 9,8765 & 6,1856 & 0 & 6,8571 \\
\hline RE & * & * & * & * & * & * & 8,8889 & 62,2951 & 20,9302 \\
\hline SA_C & * & * & * & * & * & * & * & 10,2041 & 21,4286 \\
\hline $\mathrm{TF}$ & * & * & * & * & * & * & * & * & 23,8636 \\
\hline VR_C & * & * & * & * & * & * & * & * & * \\
\hline
\end{tabular}

Quadro 2: Análise de agrupamento com base na similaridade da abundância da vegetação - relações expressas em porcentagens

Notas: DL - Dona Laura; DL_C - Dona Laura (controle); JT - General João Telles;

LA_C - Luiz Afonso (controle); MA - Machado de Assis; RE - República;

SA_C - Santo Antônio (controle); TF - Tomaz Flores; VR_C - Veríssimo Rosa (controle).

Essas análises indicam um elevado grau de similaridade entre a vegetação estudada, especialmente àquela que compõe quatro dos cinco túneis verdes selecionados. A redução da similaridade da vegetação presente em ruas deve ser um dos objetivos incluídos nos projetos de arborização viária, especialmente em propostas destinadas à 
implantação de túneis verdes, buscando-se o aumento da heterogeneidade da floresta

urbana. É importante que essa diretriz passe a ser considerada - podendo, inclusive, vir a integrar o Plano Diretor de Arborização Urbana de Porto Alegre - uma vez que o fomento da diversidade das espécies promove uma maior resiliência ambiental, inclusive em áreas urbanizadas.

Além da necessidade do plantio de uma maior gama de espécies para aumentar a diversidade da flora nas cidades, outro fator se revelou significativo durante a coleta de dados na pesquisa. Nas saídas a campo, foi possível se observar grande quantidade de vegetais sobre os exemplares de jacarandás (Jacaranda mimosifolia) e tipuanas (Tipuana tipu), ambos tipos arbóreos formadores dos túneis verdes. Todas as árvores pertencentes a essas duas espécies, com CAP superior a $1 \mathrm{~m}$, apresentam uma ou mais espécies de vegetais sobre a superfície de seus troncos ou ramos.

Entre a diversidade de plantas encontradas estão as pteridófitas Microgramma squamulosa (vegetal mais vezes observado), Nephrolepsis sp. e Rumohra adiantiformis, e as angiospermas Rhipsalis baccifera (cacto-macarrão), Hylocereus undatus (rainha-da-noite), Tillandsia stricta (cravo-do-mato), Schefflera arboricola (cheflera-pequena), Ficus pumila (unha-de-gato), Syngonium angustatum (singônio) e até vegetais de porte arbóreo como Ficus enormis (figueira). $\bigcirc$ epifitismo 6 desenvolvido por essas espécies não representa ameaça à integridade das árvores e torna mais complexa a composição vegetal dos túneis verdes, criando uma estratificação vertical útil aos pássaros e artrópodes. Com isso amplia-se a disponibilidade de flores e frutos ao longo do ano, a oferta de material para a construção de ninhos e locais para abrigo e refúgio para várias espécies. $\bigcirc$ Quadro 3 ilustra algumas das espécies vegetais encontradas sobre as tipuanas e jacarandás existentes nos túneis verdes visitados.

\section{CONSIDERAÇÕES FINAIS}

A adoção de condutas voltadas ao gerenciamento da vegetação urbana passa, obrigatoriamente, pelo reconhecimento do elemento vegetal como componente do espaço urbano, estruturador da paisagem, como agente que qualifica o ar, o clima, o solo e a ambiência urbana, de um modo geral, e de igual importância aos demais serviços de infra-estrutura. A utilização de processos dinâmicos de planejamento fundamentados em proposta de Milano (1990), e já adotados por Porto Alegre (como a realização de levantamentos, elaboração de banco de dados, existência de Plano Diretor de Arborização Urbana, entre outros) consiste em exemplo positivo da sistemática a ser implantada nas cidades, elevando a arborização ao patamar dos demais serviços de infra-estrutura, consolidado seu papel como um instrumento de gestão urbana.

Os levantamentos da vegetação realizados abordaram questões de taxonomia e contemplaram avaliações quantitativas, critérios que conduziram para uma leitura da composição real da arborização, reunindo subsídios para possíveis intervenções futuras sobre a mesma. A presente pesquisa não é restritiva, podendo ser repetida em outras cidades, sem qualquer comprometimento metodológico. 

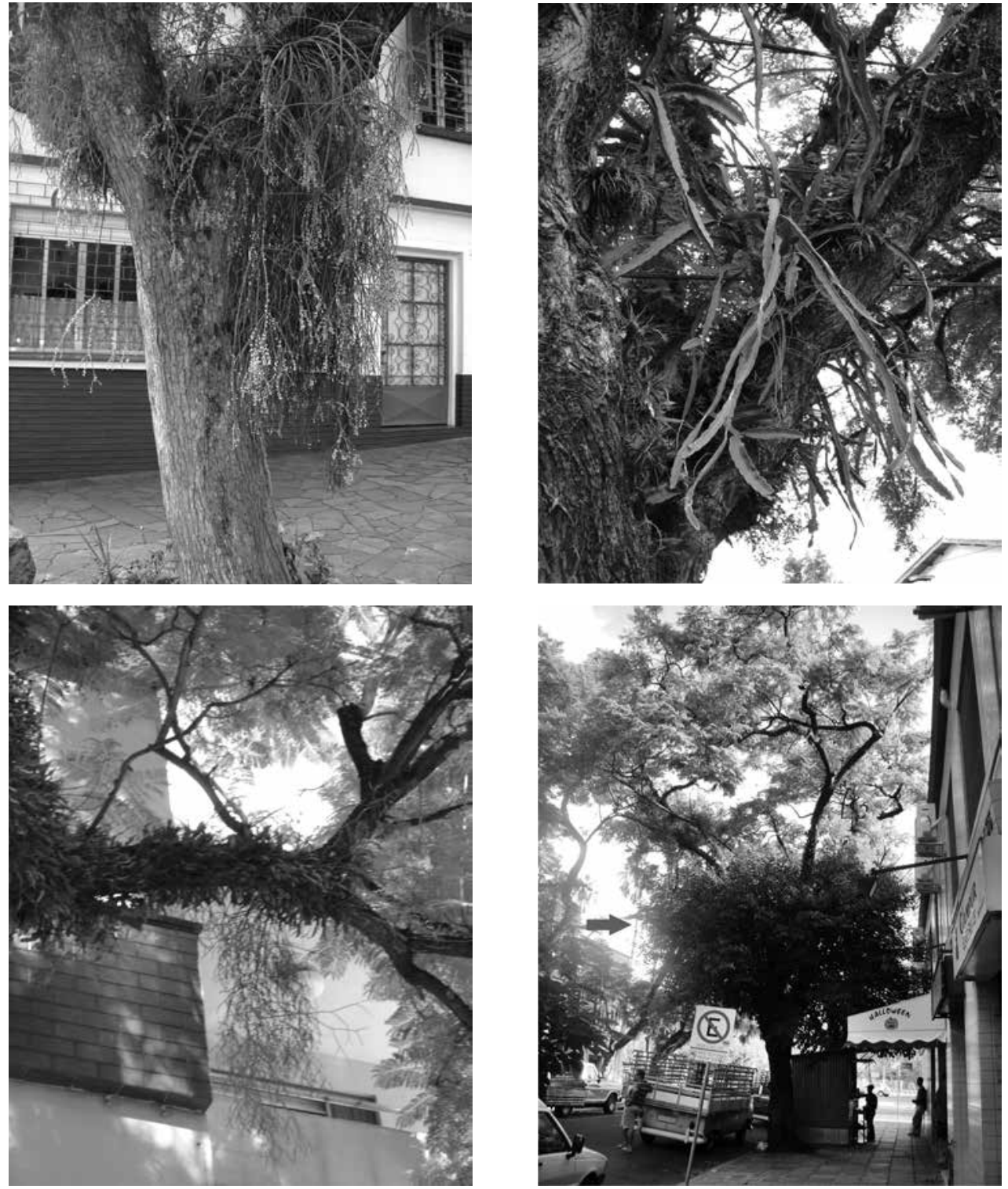

Quadro 3: Exemplos de vegetais não-parasitas encontrados sobre exemplares de tipuana (Tipuana tipu) e jacarandá-mimoso (Jacaranda mimosifolia) presentes nos túneis verdes

Notas: Imagem 1 - Rhipsalis baccifera sobre T. tipu - cactácea herbácea epífita que produz frutos brancos e arredondados atrativos à avifauna;

Imagem 2 - T. tipu como suporte a outros vegetais como Tillandsia stricta (bromélia cujas flores atraem beijaflores) e Hylocereus undatus (cactácea de flores noturnas e frutos comestíveis);

Imagem 3 - ramo de J. mimosifolia recoberto por Microgramma squamulosa (Pteridophyta); ao centro e pendente, exemplar de Rhipsalis baccifera;

Imagem 4 - Ficus enormis (seta) sobre J. mimosifolia - figueira cujos frutos amadurecem nos meses de dezembro e janeiro, atraindo várias espécies de pássaros.

Fonte: Luciane Salvi

As informações obtidas pelo estudo demonstraram a necessidade de buscar-se uma maior heterogeneidade de espécies para a composição da arborização viária, inclusive em projetos destinados à implantação de novos túneis verdes na paisagem. A utilização 
de exemplares arbóreos de grande porte mostrou-se particularmente relevante, uma vez que esses espécimes reúnem as condições físicas para dar suporte a outras espécies vegetais, ampliando a complexidade da floresta urbana e, conseqüentemente, seu potencial para acolher a biodiversidade.

\section{Notas}

(1) MILANO, M. S. Avaliação quali-quantitativa e manejo da arborização urbana: Exemplo de Maringá - PR. 1988. 120 f. Tese (Doutorado em Engenharia Florestal) - Setor de Ciências Agrárias, Universidade Federal do Paraná, Curitiba, 1988.

(2) MILANO, M. S. Planejamento e replanejamento de arborização de ruas. In: ENCONTRO NACIONAL SOBRE ARBORIZAÇÃO URBANA, 2, 1987, Maringá. Anais... Maringá: Prefeitura Municipal de Maringá, 1987, p. 1,8.

(3) Ibid., p. 64.

(4) $\bigcirc$ " $n$ " total da amostra de vegetação ao longo de todas as vias estudadas consistiu em 760 registros, mas, em decorrência da não-determinação de dois exemplares (um permaneceu sem ser identificado e outro foi apenas identificado até o nível de família), o "n" total final resultante foi de 758 indivíduos.

(5) "Os índices de abundância relativa são bastante utilizados em populações de animais e plantas terrestres maiores nas quais é indispensável obter uma medida aplicável a grandes áreas sem excessivos gastos de tempo e dinheiro." (ODUM; BARRETT, 2008, p. 227)

(6) Epifitismo - relação entre espécies, na qual uma delas busca em outra suporte, abrigo ou maior acesso à luz solar.

\section{Bibliografia}

BIONDI, D. Curso de arborização urbana. Curitiba: Universidade Federal do Paraná, 2000.

BIONDI, D.; ALTHAUS, M. Árvores de rua de Curitiba: Cultivo e manejo. Curitiba: FUPEF - Fundação de Pesquisas Florestais do Paraná, 2005.

BRASIL. Lei n. 4.771, de 15 de setembro de 1965. Institui o novo Código Florestal. Diário Oficial [da] República Federativa do Brasil. Poder Brasília: Executivo, 16 set. 1965.

BRASIL. Lei n. 7.803, de 18 de julho de 1989. Altera a redação da Lei n. 4.771, de 15 de setembro de 1965, e revoga as Leis n. 6.535, de 15 de junho de 1978, e 7.511, de 7 de julho de 1986. Diário Oficial [da] República Federativa do Brasil. Brasília: Poder Executivo, 20 jul. 1989.

FAITH, D. P.; MINCHIN, P. R.; BELBIN, L. Compositional dissimilarity as a robust measure of ecological distance. Vegetatio, Dordrecht, v. 39, p. 57-68, 1987.

FERNÁNDEZ-JURICIC, E. Avifaunal use of wooded streets in an urban landscape. Conservation Biology, Flórida, v. 14, n. 2, p. 513-521, 2000.

GIRLING, C.; KELLETT, R. Skinny streets \& green neighborhoods: Design for environment and community. Washington: Island Press, 2005.

GOOGLE EARTH MAPPING SERVICE. Imagens de satélite da cidade de Porto Alegre, 2008. Disponível em: <http://earth.google.com/intl/pt/download. earth.html>. Acesso em: 7 jan. 2008.

IBGE - INSTITUTO BRASILEIRO DE GEOGRAFIA E ESTATÍSTICA. IBGE Cidades@: Porto Alegre - RS. Brasília: Ministério do Planejamento, Orçamento e Gestão, 2006. Disponível em: <http://www.ibge.gov.br/cidadesat/default. php>. Acesso em: 20 jun. 2007.

LORENZI, H. Árvores brasileiras: Manual de identificação e cultivo de plantas arbóreas nativas do Brasil. 4. ed. Nova Odessa: Plantarum, v. 1, 2002 a.

Árvores brasileiras: Manual de identificação e cultivo de plantas arbóreas nativas do Brasil. 2. ed. Nova Odessa: Plantarum, v. 2, 2002 b.

LORENZI, H.; SOUZA, H. M. de. Plantas ornamentais no Brasil: Arbustivas, herbáceas e trepadeiras. 3. ed. Nova Odessa: Plantarum, 2001. 
LORENZI, H.; SOUZA, H. M. de; TORRES, M. A. V.; BACHER, L. B. Árvores exóticas no Brasil: Madeireiras, ornamentais e aromáticas. Nova Odessa: Instituto Plantarum, 2003.

MASCARÓ, L. E. A. R. de; MASCARÓ, J. L. Vegetação urbana. Porto Alegre: Pini, 2002.

McALEECE, N. Biodiversity Pro. Londres: Natural History Museum \& Scottish Association for Marine Science, 1997. Computer program.

MENEGAT, R.; MOHR, F. V.; CARRARO, C. C.; FLÔRES, R. Porto Alegre em dados. In: MENEGAT, R. (Coord.) Atlas ambiental de Porto Alegre. Porto Alegre: Universidade Federal do Rio Grande do Sul, 1998, p. 203.

MILANO, M. S. Planejamento da arborização urbana: Relações entre áreas verdes e ruas arborizadas. In: ENCONTRO NACIONAL SOBRE ARBORIZAÇÃO URBANA, 3., 1990, Curitiba. Anais... Curitiba: Fundação de Pesquisas Florestais do Paraná - FUPEF, 1990.

MILANO, M. S.; DALCIN, E. Arborização de vias públicas. Rio de Janeiro: Light, 2000.

MOCK, T. Implantando uma floresta urbana sustentável. Revista de Agricultura Urbana, Leusden, Holanda, n. 13, jun. 2006. Disponível em: <http://www.ipes.org/index.php?option=com_content\&view=article\&id=144\&item $\mathrm{id}=104>$. Acesso em: 10 jun. 2006.

ODUM, E. P.; BARRET, G. W. Fundamentos de ecologia. São Paulo: Cengage Learning, 2008.

PORTO ALEGRE. Lei n. 8.245, de 10 de dezembro de 1998. Institui, oficialmente, a árvore como símbolo ecológico de Porto Alegre. Diário Oficial de Porto Alegre, Porto Alegre, 15 dez. 1998, p. 2.

PORTO ALEGRE. Plano diretor de arborização de vias públicas. SANCHOTENE, M. do C. C. (Coord.). Porto Alegre: Secretaria Municipal do Meio Ambiente, 2000.

Decreto n. 15.196, de 2 de junho de 2006. Declara a rua Gonçalo de Carvalho patrimônio cultural, histórico e ecológico de Porto Alegre. Diário Oficial de Porto Alegre. 2.794 ed. Porto Alegre, 7 jun. 2006 a, p. 5.

Lei Complementar n. 551, de 8 de junho de 2006. Cria a compensação do crédito tributário do Imposto sobre Propriedade Territorial Urbana, com crédito de contribuinte municipal, líquido, certo e vencido, resultante de indenização por danos em seu bem imóvel localizado nos logradouros denominados "túneis verdes". Diário Oficial de Porto Alegre. 2.797 ed. Porto Alegre, 12 jun. 2006 b, p. 2.

Plano diretor de arborização urbana de Porto Alegre. PICCOLI, L. (Coord.). Porto Alegre: Secretaria Municipal do Meio Ambiente, 2007a.

Decreto n. 15.585, de 4 de junho de 2007. Declara Área de Uso Especial, para integrar o Patrimônio Histórico e Ecológico na rua João Mendes Ouriques. Diário Oficial de Porto Alegre, 3.041, Porto Alegre, 6 jun. 2007 b, p. 2.

Decreto n. 15.666, de 25 de setembro de 2007. Declara Área de Uso Especial, para integrar o Patrimônio Histórico e Ecológico, trecho da rua Marquês do Pombal. Diário Oficial de Porto Alegre. 3.118 ed. Porto Alegre, 26 set. 2007 c, p. 3.

Site oficial da SMAM: Secretaria Municipal do Meio Ambiente. Porto Alegre, 2008. Disponível em: <http://www2.portoalegre.rs.gov.br/smam/ default.php?>. Acesso em: 3 out. 2008.

REIS, A.; DOS ANJOS, A.; LESSA, A. P.; BECCHARA, F. C. Critérios para a seleção de espécies na arborização urbana ecológica. Sellowia, Itajaí, v. 53, p. 51-67, 2003.

SALVI, L. T. Contribuições para gestão urbana: Corredores de vegetação para avifauna em Porto Alegre, RS. 2008. 196 f. Dissertação (Mestrado em Gestão Urbana) - Centro de Ciências Exatas e Tecnologia. Pontifícia Universidade Católica do Paraná, Curitiba, 2008.

SANCHOTENE, M. do C. Situação das áreas verdes e da arborização urbana em Porto Alegre. In: ENCONTRO NACIONAL SOBRE ARBORIZAÇÃO URBANA, 3., 1990, Curitiba. Anais... Curitiba: FUPEF - Fundação de Pesquisas Florestais do Paraná, Paraná, 1990.

SANCHOTENE, M. do C.; PUENTE, A.; OLIVEIRA, F. B.; ROSO, A. L.; BARCELOS, P. R. Cidade das árvores: arborização urbana. In: MENEGAT, R. (Coord.) Atlas ambiental de Porto Alegre. Porto Alegre: Universidade Federal do Rio Grande do Sul, 1998.

SENNA, D. C. Estado actual de la información sobre arboles fuera del bosque. In: FAO - Food and Agriculture Organization of the United Nations. Información para el desarrollo forestal sostenible: estado de la información forestal en Brasil. Santiago: Comisión Europea/FAO, 2002. Disponível em: <http://ftp.fao.org/docrep/fao/006/ ad399500.pdf>. Acesso em: 30 ago. 2006.

SOUZA, V. C.; LORENZI, H. Botânica sistemática: Guia ilustrado para identificação das famílias de angiospermas da flora brasileira, baseado em APG II. Nova Odessa: Instituto Plantarum, 2005. 
Luciane Teresa Salvi, Cristiano Eidt Rovedder,

Letícia Peret Antunes Hardt, Carla Suertegaray Fontana

TÚNEL verde é patrimônio da cidade. Correio do Povo, Porto Alegre, 26 set. 2007, p. 14.

WOLF, K. L. O valor econômico e social das florestas urbanas. Revista de Agricultura Urbana, Leusden, Holanda, n. 13, 2004.

\section{Agradecimentos}

A Eraldo Barboza, do Jardim Botânico de Curitiba, pelo auxílio na identificação de exemplares vegetais.

A Harry Alberto Bollmann e Fábio Duarte - professores do Programa de Pós-Graduação em Gestão Urbana da Pontifícia Universidade Católica do Paraná - PPGTU - por suas orientações.

A Carmen Suzana Martins, do laboratório de Botânica da Pontifícia Universidade Católica do Rio Grande do Sul PUCRS, pelo empréstimo de bibliografia e pesquisas diversas.

À Fundação O Boticário de Proteção à Natureza - FBPN pelo apoio e financiamento desta pesquisa.

À Fundação Araucária de Apoio ao Desenvolvimento Científico do Paraná, pela bolsa de mestrado concedida.

À PUCPR e ao Museu de Ciências e Tecnologia da PUCRS pelo suporte logístico. 